\title{
Method for systematic targeted isolation of homologous cDNA fragments in a multiplex format
}

\author{
Reiko Ohara ${ }^{1}$, Hisashi Koga ${ }^{1,2}$, Reiko Kikuno ${ }^{1}$, and Osamu Ohara ${ }^{1,3}$ \\ ${ }^{1}$ Kazusa DNA Research Institute, Kisarazu, Chiba, Japan, ${ }^{2}$ Chiba Industry \\ Advancement Center, Chiba, Chiba, Japan, and ${ }^{3}$ RIKEN Research Center for Allergy \\ and Immunology, Yokohama, Kanagawa, Japan
}

BioTechniques 36:798-806 (May 2004)

In this study, a two-step method for systematic multiplex cloning of homologous cDNAs from related species was developed. The first step, called MUCH (multiplex cloning of homologous genes), is cloning of partial but authentic cDNA fragments of homologous cDNAs by hybridization to arrayed cRNA probes of specified genes on a nylon membrane, followed by PCR amplification of the hybridized fragments. The second step is PCR-based screening of a library that contains longer $c D N A$ inserts based on the sequences obtained in the first step. To evaluate this method, we tried to isolate mouse counterparts of 53 human large cDNAs by MUCH and could successfully isolate 32 mouse counterpart cDNAs from a single library. Complete sequencing of two mouse cDNAs isolated by PCR-based screening further demonstrated that this method enabled us to isolate multiple homologous cDNAs in parallel. We thus expect that this method could be applied to high-throughput cloning of homologous cDNAs in related species.

\section{INTRODUCTION}

As comparative genomic approaches are becoming popular in functional genomic analyses, a technique that facilitates the efficient parallel cloning of homologous cDNAs for multiple genes in related species is needed. Thus far, in the absence of partial cDNA sequence of the target gene, the most popular approach for isolation of homologous cDNA is colony hybridization, based on cross-hybridization of a probe derived from a gene of interest. However, since optimized cross-hybridization conditions vary from gene to gene, it is not easy to isolate homologous cDNA clones derived from multiple genes by colony screening based on cross-hybridization. To solve this problem, we devised a method for targeted cloning of homologous genes that enables us to isolate cDNA clones for multiple genes in parallel. In this method, we first obtain partial but authentic cDNA sequences by multiplex cloning of homologous genes $(\mathrm{MUCH})$ and then screen a cDNA library using the obtained perfect cDNA sequence information for isolation of longer cDNAs. The results shown in this study demonstrate that this method could be successfully applied to the isolation of mouse homologues of human long cDNAs, known as KIAA cDNAs (http://www.kazusa.or.jp/huge) (1).

\section{MATERIALS AND METHODS}

\section{Two-Step Homologous cDNA Cloning Strategy}

The cloning strategy that we developed in this study is shown schematically in Figure 1. Here, we used human KIAA (hKIAA) cRNAs (1) as probes to target mouse homologous cDNAs (mKIAA cDNAs).

\section{Preparation of Mouse cDNA Fragments}

Mouse brain mRNA was prepared from 6-week-old $\mathrm{BALB} / \mathrm{c}$ male mice as previously described (2). Doublestranded cDNA was synthesized from $5 \mu \mathrm{g}$ of poly(A)+ RNA using the SuperScript $^{\mathrm{TM}}$ Plasmid System (Invitrogen, Carlsbad, CA, USA). Briefly, the firststrand cDNA was synthesized using SuperScript II RNaseH ${ }^{-}$reverse transcriptase and T7-NotI-(dT) ${ }_{16}$ primer (Figure
2A); a minor modification was that the reaction was performed at $37^{\circ} \mathrm{C}$ for 30 min and then at $42^{\circ} \mathrm{C}$ for $30 \mathrm{~min}$. After SP6 adaptor (Figure 2B) ligation to both ends of double-stranded cDNA, the cDNA fragments were size-fractionated on $1 \%$ low-melting-temperature agarose gel, and cDNAs larger than $3 \mathrm{~kb}$, our targeted mKIAA size range, were retrieved $(2,3)$. Since these larger cDNA fragments were obtained in low quantities, cRNA amplification was carried out using a MEGAscript ${ }^{\mathrm{TM}} \mathrm{T} 7$ kit (Ambion, Austin, TX, USA), and the cRNA was purified with an RNeasy ${ }^{\circledR}$ Mini kit (QIAGEN, Valencia, CA, USA) before being converted to double-stranded cDNA. Double-stranded cDNA was synthesized as described above using SP6 UP primer (Figure $2 \mathrm{~B}$ ) and $3.6 \mu \mathrm{g}$ of purified cRNA. The resulting cDNA fragments were digested with HaeIII, purified with a PCR purification kit (Invitrogen), and then A-tailed with dATP and Taq DNA polymerase (Takara, Kyoto, Japan) at their $3^{\prime}$ ends by incubating at $70^{\circ} \mathrm{C}$ for $30 \mathrm{~min}$. After purification, as described above, $20 \mathrm{ng}$ of the cDNA fragments were ligated with $50 \mathrm{ng}$ pT7Blue T-Vector (Novagen, Madison,WI, USA) using T4 DNA ligase (Invitrogen) by overnight incubation at $16^{\circ} \mathrm{C}$. After phenol/chloroform/isoamyl alcohol (25:24:1) extraction followed by ethanol precipitation, the ligation mixture was suspended in water and the inserted HaeIII-digested cDNAs were amplified from 1/20 (v/v) of the ligation mixture using the PCR with Taq DNA polymerase and pT7 S1 and pT7 AS1 primers (Figure 2C). The PCR thermal cycling was performed on an iCycler ${ }^{\mathrm{TM}}$ (BIO-RAD, Hercules, CA, USA) and conditions were as follows: initial denaturation step, $95^{\circ} \mathrm{C}$ for $1 \mathrm{~min}$; amplification cycle (30 cycles), $95^{\circ} \mathrm{C}$ for $30 \mathrm{~s}, 55^{\circ} \mathrm{C}$ for $30 \mathrm{~s}$, and $72^{\circ} \mathrm{C}$ for $1 \mathrm{~min}$; final extension step, $72^{\circ} \mathrm{C}$ for $5 \mathrm{~min}$. After removing small PCR products $(<100 \mathrm{bp})$ by size fractionation on $1 \%$ low-melting-temperature agarose gel electrophoresis, the purified cDNA fragments were recovered and allowed to hybridize with probes on nylon membranes as described below.

\section{Preparation of hKIAA cRNA- Immobilized Nylon Membrane}

cRNA of each hKIAA cDNA was 


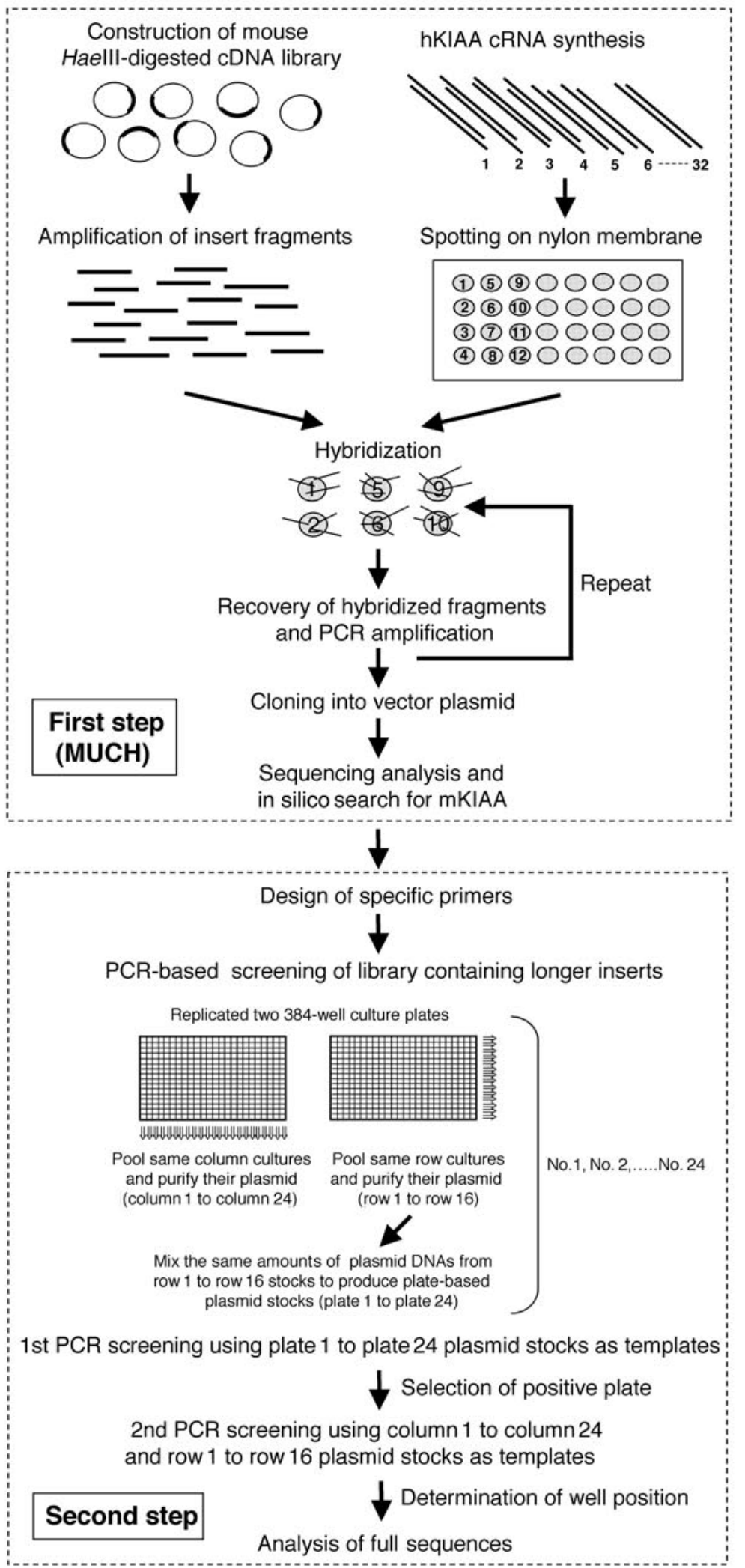

synthesized from the NotI-linearized cDNA plasmids using a MEGAscript T7 kit, followed by purification of cRNAs with an RNeasy Mini kit. After heat denaturation, $1 \mu \mathrm{L}$ of each of the cRNAs (100 $\mathrm{ng} / \mu \mathrm{L})$ was manually arrayed onto a $4.3 \times 2.8 \mathrm{~cm}$ PALL Biodyne ${ }^{\circledR}$ A membrane (PALL, East Hills, NY, USA). The membranes were baked for $2 \mathrm{~h}$ in a Vacubaker AB-1890 (ATTO, Tokyo, Japan) and UV-irradiated in a Stratalinker ${ }^{\circledR} 2400$ UV crosslinker (Stratagene, La Jolla, CA, USA).

\section{Enrichment of mKIAA cDNA Fragments by Hybridization to the hKIAA cRNA Probe}

Hybridization of mouse cDNA fragments to the hKIAA cRNAs immobilized on the nylon membrane was carried out in a hybridization vial (Mighty vial No. 2; Maruemu, Osaka, Japan) in a Hybaid Midi Dual Hybridization Oven (Thermo Electron, Beverly, MA, USA). After prehybridization with 50 $\mu \mathrm{g}$ heat-denatured mouse Cot-1 DNA ${ }^{\circledR}$ (Invitrogen) for $1 \mathrm{~h}$ at $60^{\circ} \mathrm{C}$ in $500 \mu \mathrm{L}$ PerfectHyb $^{\text {TM }}$ buffer (TOYOBO, Osaka, Japan), the cRNA-spotted nylon membrane was subjected to hybridization in $250 \mu \mathrm{L}$ PerfectHyb buffer containing 200 ng heat-denatured PCR-amplified

Figure 1. Isolation of homologous cDNAs. The first step, multiplex cloning of homologous genes (MUCH), was developed to obtain partial but authentic sequences of targeted genes. The determined sequences were used for primer design to select clones by PCR-based screening in the second step. To perform two-step PCR-based screening, duplicate sets of culture plates were prepared from the master plates. One plate was used for 24 pools of the same column cultures and the other was used for 16 pools of the same row cultures. Plasmid DNAs were purified from these pooled cultures using an MFX-9600 Magnia ${ }^{\circledR}$ Nucleic Acid Purification System (TOYOBO). For preparation of the plate-pooled plasmid DNAs, an equal amount of 16 row-pooled plasmid DNAs were mixed. In the first round of screening, these 24 plate-pooled plasmid DNAs were used as templates for PCR and the plate containing a target clone was identified by gel electrophoresis. In the second round of screening, 24 column-pooled plasmid DNAs and 16 row-pooled plasmid DNAs of the positive plate were used as templates for PCR and then the location of the well containing the positive clone was determined, as in the first round of screening. Each PCR was performed in $10 \mu \mathrm{L}$ of reaction mixture containing the mKIAA specific primers, Taq DNA polymerase and antiTaq High, with a GeneAmp ${ }^{\circledR}$ PCR system 9700 (Applied Biosystems, Foster City, CA, USA). 
mouse cDNA fragments, $50 \mu \mathrm{g}$ mouse Cot-1 DNA, and $2 \mu \mathrm{g}$ polyadenylic acid. After overnight hybridization at $60^{\circ} \mathrm{C}$, the membrane was successively washed in $2 \times$ standard saline citrate (SSC) $/ 0.1 \%$ sodium dodecyl sulfate (SDS) at room temperature for $5 \mathrm{~min}$, at $60^{\circ} \mathrm{C}$ for $15 \mathrm{~min}$, and finally twice in $0.1 \times \mathrm{SSC} / 0.1 \% \mathrm{SDS}$ at $60^{\circ} \mathrm{C}$ for 20 min. After being briefly rinsed with water, each cRNA-spotted area of the nylon membrane was cut out using a disposable biopsy punch (3- $\mathrm{mm}$ diameter; BP-30K, Kai Industry, Gifu, Japan). The excised membranes were transferred separately into $0.5-\mathrm{mL}$ tubes, or to wells in a 96-well plate, and then washed with $100 \mu \mathrm{L}$ of water at $65^{\circ} \mathrm{C}$ for $10 \mathrm{~min}$. Finally, the hybridized mouse cDNA fragments were eluted from the excised membrane in $100 \mu \mathrm{L}$ of water by incubation at $95^{\circ} \mathrm{C}$ for $5 \mathrm{~min}$. Ten microliters of each eluate were subjected to hot-start PCR on an iCycler using Taq DNA polymerase, anti-Taq High (TOYOBO) and pT7 S1 and pT7 AS1 primers in $50 \mu \mathrm{L}$ under the same conditions described for preparation of mouse cDNA fragments. After the amplification, $5 \mu \mathrm{L}$ of each PCR mixture were electrophoresed on $3 \%$ NuSieve ${ }^{\circledR}$ 3:1 agarose gel (Cambrex, East Rutherford, NJ, USA), and the amount of each PCR product was estimated by comparison with fluorescent staining intensities of known amounts of DNA using ImageQuant ${ }^{\mathrm{TM}}$ software (version 5.0) on a FluoroImager 595 (Amersham Biosciences, Piscataway,
NJ, USA). For further enrichment, the hybridization-based capture of the amplified mKIAA cDNA fragments was carried out with pre-excised pieces of cRNA-spotted nylon membrane in either a $0.5-\mathrm{mL}$ tube or a well in a $96-$ well plate. The hybridization for this second-round enrichment was performed in $100 \mu \mathrm{L}$ PerfectHyb buffer containing 20-30 ng heat-denatured amplified mKIAA cDNA fragments, 1 $\mu \mathrm{g}$ polyadenylic acid, and $10 \mu \mathrm{g}$ mouse Cot- 1 DNA at $60^{\circ} \mathrm{C}$ for $3 \mathrm{~h}$. The washing steps, the elution step, and PCR were performed exactly as described for the first-round enrichment, except that nested PCR primers (pT7 S2 and pT7 AS2; Figure 2C) were used for the PCR in the second-round enrichment.

\section{Identification of mKIAA cDNA Fragments by Sequencing}

As all of the PCR-amplified cDNAs should contain SalI and BamHI sites close to the end of each fragment (as seen Figure 2C), the second-round PCR products were double-digested with these endonucleases, purified using the PCR purification kit, and then ligated into SalI-BamHI digested pSPORT 1 vector (Invitrogen). The ligation products were introduced into DH5 $\alpha^{\mathrm{TM}}$ competent cells (Invitrogen) by chemical transformation. Eight to thirty transformants were randomly picked and their insert fragments were amplified by direct colony PCR using M13 forward and T7 primers and

\section{A 5'-GACGCGTAATACGACTCACTATAGGCGGCCGCTTTTTTTTTTTTTTTTT-3' T7 promoter NotI \\ B 5'-GGACGCGTATTTAGGTGACACTATAGAAG-3' 3'-TGCGCATAAATCCACTGTGATATCTTC-P-5'

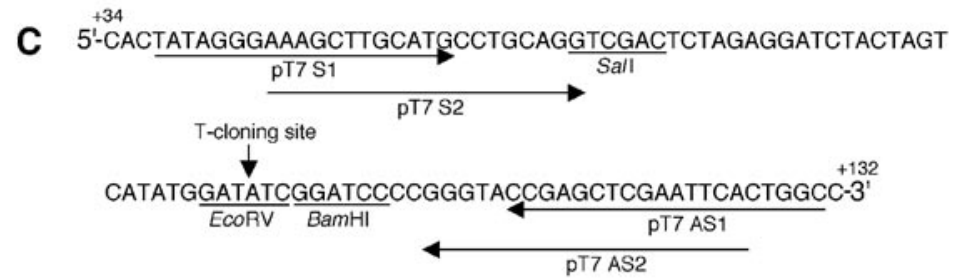

Figure 2. Primer and adaptor sequences designed for construction of mouse Hae III cDNA library. (A) T7-NotI-(dT) ${ }_{16}$ primer sequence. (B) SP6 adaptor sequence. This adaptor was prepared by self-annealing of the upper 29-mer oligonucleotide (also used as SP6 UP primer) and lower 27-mer oligonucleotide. In the latter, $5^{\prime}$ cytidine-deoxyribose was phosphorylated, indicated as -P. (C) Primers designed in the region of the multiple cloning site in pT7Blue T-vector. Mouse HaeIII cDNA fragments were ligated into the EcoRV T-cloning site. processed for sequencing analysis as previously described (3). The obtained cDNA sequences were subjected to a BLAST search against our in-house human cDNA database constructed from public DNA sequence databases by eliminating as many expressed sequence tags (ESTs) and genomic sequences as possible. Query cDNA fragments that showed the best homology to the probed hKIAA were selected as candidate mKIAA cDNAs.

\section{PCR-Based Screening of cDNA Library}

After obtaining authentic mouse cDNA sequences as described above, specific primers for each mKIAA cDNA were designed using OLIGO $^{\mathrm{TM}}$ Primer Analysis Software (MBI, Cascade, CO, USA) and prepared for PCR-based screening of a cDNA library. Each randomly sampled cDNA clone selected from a size-fractionated mouse brainderived cDNA library (9-11 kb plasmid size) (2) was separately cultured in a

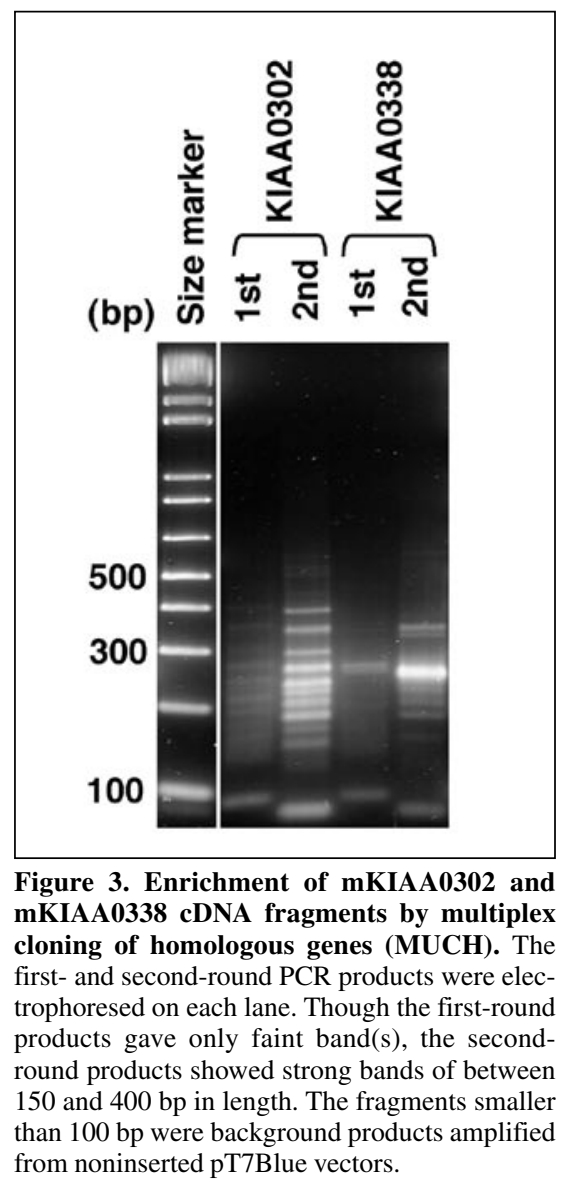


Table 1. mKIAA cDNA Fragments Isolated by $\mathrm{MUCH}^{\mathrm{a}}$

\begin{tabular}{|c|c|c|c|c|c|c|c|}
\hline $\begin{array}{c}\text { mKIAA } \\
\text { No. }\end{array}$ & $\begin{array}{l}\text { Sequence } \\
\text { Identity to } \\
\text { hKIAA } \\
(\%)\end{array}$ & $\begin{array}{c}E \\
\text { Value }\end{array}$ & $\begin{array}{l}\text { Hit Length } \\
\text { (nt) }\end{array}$ & $\begin{array}{c}\text { mKIAA } \\
\text { No. }\end{array}$ & $\begin{array}{c}\text { Sequence } \\
\text { Identity to } \\
\text { hKIAA } \\
\text { (\%) }\end{array}$ & $\begin{array}{c}\mathrm{E} \\
\text { Value }\end{array}$ & $\begin{array}{l}\text { Hit Length } \\
\text { (nt) }\end{array}$ \\
\hline 0284 & 80.0 & $1.5 \times 10^{-129}$ & 261 & \multirow[t]{2}{*}{1814} & \multirow{2}{*}{$\begin{array}{l}88.2 \\
89.5 \\
90.3\end{array}$} & \multirow{2}{*}{$\begin{array}{l}3.6 \times 10^{-150} \\
1.5 \times 10^{-101} \\
2.4 \times 10^{-82}\end{array}$} & 228 \\
\hline 0294 & $\begin{array}{l}83.4 \\
83.0\end{array}$ & $\begin{array}{l}9.0 \times 10^{-205} \\
4.0 \times 10^{-143}\end{array}$ & $\begin{array}{l}344 \\
247\end{array}$ & & & & $\begin{array}{l}153 \\
124\end{array}$ \\
\hline 0297 & $\begin{array}{l}90.5 \\
90.0\end{array}$ & $\begin{array}{l}3.4 \times 10^{-138} \\
7.3 \times 10^{-61}\end{array}$ & $\begin{array}{l}200 \\
102\end{array}$ & $\begin{array}{l}1821 \\
1828\end{array}$ & $\begin{array}{l}84.8 \\
85.5\end{array}$ & $\begin{array}{l}1.2 \times 10^{-202} \\
1.6 \times 10^{-91}\end{array}$ & $\begin{array}{l}329 \\
162\end{array}$ \\
\hline 0300 & 80.0 & $4.4 \times 10^{-71}$ & 140 & 1831 & \multirow{4}{*}{$\begin{array}{l}88.9 \\
88.2 \\
84.5 \\
87.5\end{array}$} & \multirow{4}{*}{$\begin{array}{l}2.5 \times 10^{-125} \\
5.5 \times 10^{-122} \\
1.8 \times 10^{-56} \\
7.5 \times 10^{-36}\end{array}$} & \multirow{4}{*}{$\begin{array}{r}189 \\
187 \\
139^{c} \\
64\end{array}$} \\
\hline 0303 & 85.6 & $3.8 \times 10^{-69}$ & 118 & & & & \\
\hline 0308 & 93.8 & $1.4 \times 10^{-55}$ & 81 & & & & \\
\hline 0309 & 88.2 & $2.0 \times 10^{-111}$ & 181 & & & & \\
\hline & 85.6 & $2.2 \times 10^{-92}$ & 163 & \multirow[t]{3}{*}{1833} & \multirow{3}{*}{$\begin{array}{l}83.1 \\
84.2 \\
90.7\end{array}$} & \multirow{3}{*}{$\begin{array}{l}6.8 \times 10^{-108} \\
5.2 \times 10^{-76} \\
4.2 \times 10^{-59}\end{array}$} & \multirow{2}{*}{$\begin{array}{l}189 \\
133\end{array}$} \\
\hline 0310 & 87.4 & $3.5 \times 10^{-144}$ & 223 & & & & \\
\hline 0311 & 95.4 & $3.4 \times 10^{-169}$ & 219 & & & & 100 \\
\hline & $\begin{array}{l}90.6 \\
95.8\end{array}$ & $\begin{array}{l}6.0 \times 10^{-143} \\
2.9 \times 10^{-127}\end{array}$ & $\begin{array}{l}215 \\
166\end{array}$ & 1836 & $\begin{array}{l}76.3 \\
84.4\end{array}$ & $\begin{array}{l}1.0 \times 10^{-107} \\
2.0 \times 10^{-102}\end{array}$ & $\begin{array}{l}358 \\
199\end{array}$ \\
\hline 0313 & 83.6 & $8.5 \times 10^{-190}$ & 318 & \multirow{3}{*}{1837} & & \multirow{3}{*}{$\begin{array}{l}1.2 \times 10^{-53} \\
6.8 \times 10^{-201} \\
5.9 \times 10^{-106} \\
6.8 \times 10^{-77}\end{array}$} & \multirow{2}{*}{$\begin{array}{r}95 \\
282\end{array}$} \\
\hline & 83.8 & $1.0 \times 10^{-141}$ & 240 & & \multirow{2}{*}{$\begin{array}{l}91.1 \\
92.6 \\
87.2\end{array}$} & & \\
\hline 0319 & 85.2 & $4.3 \times 10^{-127}$ & 209 & & & & $\begin{array}{l}282 \\
149\end{array}$ \\
\hline 0323 & $\begin{array}{l}84.0 \\
87.6 \\
77.2\end{array}$ & $\begin{array}{l}1.6 \times 10^{-153} \\
1.7 \times 10^{-69} \\
1.6 \times 10^{-17}\end{array}$ & $\begin{array}{r}263 \\
113 \\
60\end{array}$ & 1843 & $\begin{array}{l}87.2 \\
87.1 \\
92.8\end{array}$ & $\begin{array}{l}2.3 \times 10^{-104} \\
2.4 \times 10^{-119}\end{array}$ & $\begin{array}{l}125 \\
173 \\
166\end{array}$ \\
\hline 0353 & 84.9 & $5.1 \times 10^{-73}$ & 126 & \multirow[t]{2}{*}{1848} & 89.5 & \multirow{2}{*}{$\begin{array}{l}1.5 \times 10^{-101} \\
3.4 \times 10^{-42} \\
3.7 \times 10^{-29}\end{array}$} & \multirow{2}{*}{$\begin{array}{r}153 \\
79 \\
51\end{array}$} \\
\hline 0364 & $\begin{array}{l}92.1 \\
91.1\end{array}$ & $\begin{array}{l}9.7 \times 10^{-127} \\
7.5 \times 10^{-67}\end{array}$ & $\begin{array}{l}178 \\
101\end{array}$ & & $\begin{array}{l}87.2 \\
90.2\end{array}$ & & \\
\hline 0380 & $\begin{array}{l}90.1 \\
89.4\end{array}$ & $\begin{array}{c}0 \\
2.7 \times 10^{-208}\end{array}$ & $\begin{array}{l}434 \\
303\end{array}$ & \multirow[t]{2}{*}{1849} & $\begin{array}{l}76.1 \\
74.8\end{array}$ & $\begin{array}{l}4.9 \times 10^{-126} \\
4.3 \times 10^{-96} \\
4.2 \times 10^{-59}\end{array}$ & $\begin{array}{l}287 \\
223\end{array}$ \\
\hline 1805 & $\begin{array}{l}89.3 \\
93.0\end{array}$ & $\begin{array}{l}5.8 \times 10^{-165} \\
2.2 \times 10^{-101}\end{array}$ & $\begin{array}{l}243 \\
142\end{array}$ & & 88.4 & $\begin{array}{l}4.2 \times 10^{-59} \\
1.6 \times 10^{-17}\end{array}$ & $\begin{array}{l}109 \\
54^{b}\end{array}$ \\
\hline 1808 & $\begin{array}{l}86.1 \\
84.8 \\
89.9 \\
89.2\end{array}$ & $\begin{array}{l}3.2 \times 10^{-216} \\
3.0 \times 10^{-139} \\
5.9 \times 10^{-106} \\
2.3 \times 10^{-104}\end{array}$ & $\begin{array}{l}339 \\
230 \\
158 \\
158\end{array}$ & 1855 & $\begin{array}{l}90.7 \\
84.8 \\
87.5 \\
77.8\end{array}$ & $\begin{array}{l}2.3 \times 10^{-141} \\
9.4 \times 10^{-59} \\
1.1 \times 10^{-57} \\
4.8 \times 10^{-92}\end{array}$ & $\begin{array}{r}218 \\
132^{c} \\
96 \\
189\end{array}$ \\
\hline 1811 & $\begin{array}{l}87.5 \\
93.7 \\
88.2\end{array}$ & $\begin{array}{l}1.4 \times 10^{-179} \\
7.4 \times 10^{-129} \\
7.8 \times 10^{-45}\end{array}$ & $\begin{array}{r}280 \\
175 \\
76\end{array}$ & 1862 & 82.4 & $3.0 \times 10^{-43}$ & $\begin{array}{r}109 \\
85\end{array}$ \\
\hline $\begin{array}{l}\text { Mean val } \\
\text { homologe } \\
\text { significan } \\
\text { aAfter mK } \\
\text { in-house } \\
\text { b,cAll of th } \\
\text { "b" (hit }\end{array}$ & $\begin{array}{l}\text { was } 86.8 \% \text { for } \\
\text { genes. E (exp } \\
\text { ee hit. } \\
\text { A cDNAs were } \\
\text { ASTA program } \\
\text { cDNA fragmen } \\
5^{\prime} \text { untranslated }\end{array}$ & $\begin{array}{l}\text { sequence identi } \\
\text { ect) value is an } \\
\text { selected out by } \\
\text { s were hit to co }\end{array}$ & $\begin{array}{l}y \text { to hKIAA and } \\
\text { stimate of statis } \\
\text { the BLAST se } \\
\text { ing sequences }\end{array}$ & $\begin{array}{l}\text { nucleotid } \\
\text { I significa } \\
\text {, each } m \\
\text { e corres }\end{array}$ & $\begin{array}{l}\text { (nt) for hit len } \\
\text { e; the lower th } \\
\text { AA was aligne } \\
\text { nding hKIAA g }\end{array}$ & $\begin{array}{l}\text { E. MUCH, multi } \\
\text { to orthologous } \\
\text { nes except for }\end{array}$ & $\begin{array}{l}\text { ex cloning of } \\
\text { e statistically } \\
\text { KIAA by our } \\
\text { ose noted as }\end{array}$ \\
\hline
\end{tabular}

and the PCR amplification efficiency in $\mathrm{MUCH}$, the cDNAs to be screened were downsized by restriction enzymes with fourbase recognition. Since the nucleotide sequence identity between homologous cDNAs usually varies along the molecule, the downsizing of cDNAs would also make it possible to apply stringent hybridization conditions in $\mathrm{MUCH}$ because highly conserved regions should be retrieved even under these conditions. This would allow us to carry out hybridization against multiple different probes under the constant conditions. To avoid artifactual amplification of cDNAs from immobilized probes by PCR, we used cRNA, in place of cDNA, as immobilized probe on the nylon membrane.

To establish optimum conditions for $\mathrm{MUCH}$, we first carried out cloning of two mouse cDNAs homologous to hKIAA0302 (spectrin $\beta$ III) and hKIAA0338 (type I brain $4.1 / 4.1 \mathrm{~N}$ ) because their mRNA levels in the brain were relatively high $(5,6)$, thereby making them suitable controls. Figure 3 shows the gel image of PCR products after the first- and the second-round enrichment for mKIAA0302 and mKIAA0338 cDNAs under the hybridization conditions described in Materials and Methods. In both the mKI-

single well of a 384-well plate to make 24 master plates of mKIAA clones (total 9216 clones). Using these master plates, PCR-based screening of the cDNA clones was performed, essentially as described by Chinault et al. (4), which is illustrated in the lower panel of Figure 1 and described in detail in its legend. The isolated cDNAs were characterized by entire sequencing using a shotgun strategy as described previously (3).

\section{RESULTS AND DISCUSSION}

\section{Isolation of mKIAA0302 and mKIAA0338 cDNA Fragments by MUCH}

The first step, termed MUCH (Figure 1), was carried out to determine the exact sequences of partial cDNA fragments of homologous genes. To improve the hybridization kinetics
AA0302 and mKIAA0338 cDNAs, it was evident that there were more products after the second-round enrichment than after the first round. Results of Southern hybridization using rat KIAA0302 or KIAA0338 probes $(5,6)$ suggested that most of fragments seen in Figure 3 were actually derived from mKIAA0302 or mKIAA0338 cDNAs, as expected (data not shown). After cloning the secondarily enriched cDNA 
fragments, we analyzed the sequences of each set of 10 randomly isolated clones. The results showed that nine clones (six independent cDNA groups) and seven clones (four independent cDNA groups) contained cDNA fragments of the highest similarity to hKIAA0302 and to hKIAA0338, respectively. The nucleotide sequences of all of the isolated cDNA fragments (from 66 to $347 \mathrm{bp}$ in length) corresponded to coding sequences (CDSs) of hKIAA0302 or hKIAA0338, with the sequence identities ranging from $81.4 \%$ to $93.1 \%$. Thus, we considered that the conditions of hybridization, washing, elution, and amplification used were stringent enough for the isolation of homologous cDNA fragments.

\section{Parallel Isolation of Multiple mKIAA cDNA Fragments by MUCH}

Next, we applied the MUCH technique for the parallel isolation of multiple mKIAA cDNA fragments. In practice, we attempted to isolate 53 mKIAA cDNAs by either a tube reaction ( 21 mKIAA) or a 96-well plate reaction (32 mKIAA). The 96-well plate format was designed to test the feasibility of using MUCH for high-throughput cloning.

Table 1 summarizes the results of MUCH. Thirty-two mKIAA cDNAs were obtained and classified into 66 independent cDNA groups. The success rates in the tube format and the plate format were $71.4 \%(15 / 21)$ and $53.1 \%$ (17/32), respectively, and the overall success rate was $60.4 \%(32 / 53)$. The nucleotide sequence identities of these KIAA homologous cDNA fragments ranged from $74.1 \%$ to $95.8 \%$ with a mean value of $86.8 \%$ (the mean length was $182 \mathrm{bp}$ ). The observed mean value was very close to that reported as the mean value of the sequence identity between mouse and human orthologous genes by Makalowsky et al. (7). Among the 66 cDNA fragments thus isolated, 63 fragments originated from CDSs of their corresponding hKIAA genes while three fragments were from the $5^{\prime}$ or $3^{\prime}$ untranslated region (UTR). In addition, although we were not sure whether this method would enable the isolation of cDNAs that did not contain any conserved protein domains, the successful isolation of mKIAA0323, mKIAA1833, and
mKIAA1843 cDNA fragments clearly showed that the presence of conserved protein domains was not prerequisite.

\section{PCR-Based Screening and Sequencing of the Isolated mKIAA cDNA Clones}

Based on the obtained sequences of mKIAA cDNA fragments, we designed gene-specific PCR primers and screened out full-length cDNA clones from a previously constructed library (2). As a demonstration, we carried out isolation of cDNA clones for mKIAA 1828 and mKIAA1831. We isolated one positive clone for each gene by PCR-based screening and then determined their insert sequences. The total nucleotide lengths of the isolated mKIAA1828 and mKIAA1831 cDNAs were 2921 and 2923 bp with CDS sizes of 587 and 481 amino acid residues, respectively. These isolated cDNA insert sizes were much smaller than expected because the cDNA plasmids were isolated as a plasmid dimer. These nucleotide sequences were deposited to the DNA Data Bank of Japan (DDBJ), GenBank $^{\circledR}$, and the European Molecular Biology (EMBL) databases under the accession numbers AB096262 for the mKIAA1828 cDNA and AB096263 for the mKIAA1831 cDNA. By referring to a human-mouse homology map (http://www.ensembl.org/Mus musculus/syntenyview/), it was confirmed that both the mKIAA1828 and mKIAA1831 cDNAs mapped to the chromosomal location predicted by the conserved synteny between human and mouse. Therefore, we concluded that our system worked efficiently in the isolation of orthologous genes.

\section{ACKNOWLEDGMENTS}

The authors thank Drs. H. Yamakawa and N. Okazaki for technical advice, and Ms. Akiko Ukigai and Mr. Takashi Watanabe for technical help. This study was supported by a grant from the Kazusa DNA Research Institute.

\section{REFERENCES}

1.Nagase T., R. Kikuno, and O. Ohara. 2001. Prediction of the coding sequences of uniden- tified human genes. XXII. The complete sequences of 50 new cDNA clones which code for large proteins. DNA Res. 8:319-327.

2.Ohara, O., T. Nagase, G. Mitui, H. Kohga, R. Kikuno, S. Hiraoka, Y. Takahashi, S. Kitajima, et al. 2002. Characterization of size-fractionated cDNA libraries generated by in vitro recombination-assisted method. DNA Res. 9:47-57.

3.Okazaki, N. R. Kikuno, R. Ohara, S. Inamoto, Y. Hara, T. Nagase, O. Ohara, and H. Koga. 2002. Prediction of the coding sequences of mouse homologues of KIAA gene: I. The complete nucleotide sequences of 100 mouse KIAA-homologous cDNAs identified by screening of terminal sequences of cDNA clones randomly sampled from size-fractionated libraries. DNA Res. 9:179-188.

4.Chinault, A.C. and N.L. Sternberg. 2000. Screening large-insert libraries by PCR, unit 5.5. In N.C. Dracopoli, J.L. Haines, B.R Korf, D.T. Moir, C.C. Morton, C.E. Seidman, J.G. Seidman, D.R. Smith (Eds.), Current Protocols in Human Genetics. John Wiley \& Sons, New York.

5.Ohara, O., R. Ohara, H. Yamakawa, D. Nakajima, and M. Nakayama. 1998. Characterization of a new spectrin gene which is predominantly expressed in brain. Mol. Brain Res. 57:181-192.

6. Yamakawa, H., R. Ohara, D. Nakajima, M. Nakayama, and O. Ohara. 1999. Molecular characterization of a new member of the protein 4.1 family (brain 4.1) in rat brain. Mol. Brain Res. 70:197-209.

7.Makalowski, W. and M.S. Boguski. 1998. Evolutionary parameters of the transcribed mammalian genome: An analysis of 2,820 orthologous rodent and human sequences. Proc. Natl. Acad. Sci. USA. 95:9407-9412.

Received 8 December 2003; accepted 23 February 2004.

Address correspondence to Reiko Ohara, Department of Human Gene Research, Kazusa DNA Research Institute, Kisarazu, Chiba 292-0818, Japan. e-mail: ohreiko@kazusa.or.jp 